epoxy resin systems (ERS). Yet little is known about the risk when using up-to-date skin protection. Occupational skin exposure is rarely monitored and skin exposure to ERS is often left unrecognized. The objective of this project is to analyze the risk of sensitization and ACD among workers handling ERS and to assess a novel approach to optimize the prevention of dermatitis and sensitization by fluorescence visualization of exposure.

Skin exposure will be visualized by a fluorescent tracer added to the ERS. UVA-light will illuminate the skin and the fluorescent areas will be recorded by a computer vision system with a limit of detection of $1 \times 1 \mathrm{~mm}$. In cooperation with global manufacturers of wind turbines, we will randomize 350 lamination workers to either an intervention or a control group. The intervention group will be shown images of their UVA-exposed skin, while the control group will not. The intervention will take place daily in 4 time periods, each lasting a month, during the 2 year follow-up period. All participants will be patch tested at baseline and at the end of follow-up with a tailored patch-test series containing 11 different products including epoxy resins and hardeners, in total comprising 30 potentially sensitizing compounds, that the workers handle. Participants are screened for dermatitis at start and at end of follow-up or end of employment. We will analyze the risk of sensitization, dermatitis and the risk of developing dermatitis when sensitized. We will also assess determinants for ERS exposure including working tasks and procedures. The potency of resins and hardeners to elicit contact allergy will be highlighted, as well as the frequency of concomitant contact allergies to different ERS compounds.

\section{P.2.07 TIMES OF SICK LEAVE DUE TO TEMPORARY DISABILITY RELATED TO A NON-WORK-RELATED ILLNESS AND RE-ADAPTATION TO WORK}

${ }^{1}$ Adriano Dias*, ${ }^{1}$ João Marcos Bernardes* ${ }^{2}$ Juan Gomez-Salgado, ${ }^{2}$ Carlos Ruiz-Frutos. ${ }^{1}$ Botucatu Medical School/Paulista State University, Botucatu, Brazil; ${ }^{2}$ University of Huelva, Huelva, Spain

\subsection{6/OEM-2019-EPI.242}

Objective To evaluate if the times of sick leave due to temporary disability related to a non-work-related illness (NWRI) depends on whether or not the workers have required a vocational rehabilitation.

Method Historical cohort study of university workers in São Paulo, Brazil, between 2010 and 2015. Data were obtained from work institutional databases that recorded personal, occupation, physician's examination and vocational rehabilitation data. The Charlson Comorbidity Index was obtained from medical history according to the most prevalent diagnoses in each physician's assessment report and respective sick leave episode duration. Associations between variables were analyzed by simple and multiple Cox regression models.

Results Depressive disorders, convalescences and back pain were responsible for $70 \%$ of all sick leaves due to non-workrelated conditions that caused temporary disability. Follow-up time was decreased when the number of NWRI per worker increases, follow-up times until readaptation between 4 and 320 days and great variability within the same disease. The CCI weight was of 0 in $96.2 \%$ of sick leaves. In the Cox model, the number of physician's examinations $(\mathrm{HR}=0.96)$, non-insulin-dependent diabetes mellitus $(\mathrm{HR}=0.40)$ and primary essential hypertension $(\mathrm{HR}=0.29)$ were found to be significant protective factor for sick leave duration until vocational rehabilitation. Recurrent depressive disorders $(\mathrm{HR}=1.5)$, conjunctivitis $(\mathrm{HR}=2.78)$, acute sinusitis $(\mathrm{HR}=4.99)$, skin conditions $(\mathrm{HR}=3,80)$, back pain $(\mathrm{HR}=1.62)$, kidney and ureter calculus $(\mathrm{HR}=2.31)$, pelvic abdominal pain $(\mathrm{HR}=2.33)$ and falls at the same level $(\mathrm{HR}=3.71)$ were risk factors to longer sick leave duration until vocational rehabilitation.

Conclusion When there was more medical assessment during the period of sick leave the times were reduced and some diseases such as upper airways, eyes and skin, pain and depression require longer times until vocational rehabilitation.

\section{P.2.09 HEALTH RISKS OF WORKER WHO WORK WITH THE INFECTIOUS AND HEALTH CARE WASTE TRANSPORTATION FROM HOSPITAL BY PRIVATE TRANSPORT SECTOR}

Anong Hansakul*. Department of Public Health Faculty of Physical Education Srinakharinwirot University, Ongkharak, Thailand

\subsection{6/OEM-2019-EPI.243}

Infectious and health care waste dramatically increasing due to the varieties of health care activities. This aims to identify problems and the health risk of worker who work with the infectious and health care waste transportation from hospital by private transport sector (PTS). The cross-sectional study was applied to the factors effecting with the outcome. 13 PTSs and 127 workers were employed in this study. The results found that: total of 127 workers from 13 PTSs in Thailand, among this $86.6 \%$ of workers were male, mean age of 31 years old, and the mean of working with infection and health care waste of 5.03 years. The main job specification was health care waste collector of $57.5 \%$, drivers of $26 \%$, both driver and collector of $16.5 \%$. Only $38.6 \%$ was trained (control, precaution and protection) by the Ministry of Public Health (MoPH). A part one year later, the worker had an accident or injury (punch with needle or other sharp) from infectious and health care waste during working $42.5 \%$, $37.8 \%$ have had contaminated or touch with the infectious fluid, $18.9 \%$ had traffic accident (car turnover, clash, offside cone) and $8.3 \%$ had the infectious and health care waste or leachates flood pour out from vehicle or container. The factors associated with risk of the health of the infectious and health care waste worker taken into account of affect of other factors, it were found that prevention and precaution training, job position, age and yearly health check were statistical significant with the health risk, respectively $(\mathrm{OR}=4.61,95 \%$ $\mathrm{CI}=0.26$ to $1.44, \mathrm{p}=0.01) \quad$ job position $(\mathrm{OR}=3.68, \quad 95 \%$ $\mathrm{CI}=1.09$ to $12.35, \mathrm{p}=0.05)$, Age $(\mathrm{OR}=2.97,95 \% \mathrm{CI}=0.16$ to $48.49, \mathrm{p}=0.01)$ and yearly health check $(\mathrm{OR}=0.96,95 \%$ $\mathrm{CI}=0.34$ to $2.72, \mathrm{p}=0.01)$.

\section{P.2.10 HEALTHCARE PROVIDER COMMUNICATION AND THE DURATION OF TIME OFF WORK AMONG INJURED WORKERS: A PROSPECTIVE COHORT STUDY}

\footnotetext{
${ }^{1}$ Tyler Lane, ${ }^{2}$ Rebbecca Lilley, ${ }^{3}$ Ollie Black, ${ }^{1}$ Malcolm Sim, ${ }^{1,4,5}$ Peter Smith. ${ }^{1}$ Monash University, Melbourne, Australia; ${ }^{2}$ University of Otago, Dunedin, New Zealand; ${ }^{3}$ Deakin University, Geelong, Australia; ${ }^{4}$ Institute for Work and Health, Toronto, Canada; ${ }^{5}$ University of Toronto, Toronto, Canada
}

10.1136/OEM-2019-EPI.244 